\title{
KESEDIHAN TOKOH UTAMA DALAM KUMPULAN PUISI KARYA ANNE BRONTE
}

\author{
Icha Choirunisa Herawan \\ Program Studi Sastra Inggris, Fakultas Administrasi dan Humaniora \\ Universitas Muhammadiyah Sukabumi \\ Choirunnisa.icha1@gmail.com
}

\begin{abstract}
The title of this research is Kesedihan Tokoh Utama dalam Kumpulan Puisi Karya Anne Bronte. The aims of this research is to find the representation the sadness of the main character who described by Anne Bronte in her collection poems through the deep structure of the poem which includes; theme, tone, feeling and mandate. The method of this research is qualitative descriptive. The approach of this research is literary objective approach. The result of this research show the sadness of the main characters who described in the Anna Bronte collection poems are caused by logging, loneliness and losing which through by the main characters itself of their lives.
\end{abstract}

\section{Keywords: Deep structure of the poem, Main character, Sadness}

\begin{abstract}
ABSTRAK
Judul yang digunakan dalam penelitian ini adalah Kesedihan Tokoh Utama dalam Kumpulan Puisi Karya Anne Bronte. Penelitian ini bertujuan untuk mengetahui kesedihan tokoh utama yang digambarkan Anne Bronte dalam kumpulan puisinya melalui struktur batin puisi yang meliputi tema, nada, rasa dan amanat. Metode yang digunakan dalam penelitian ini adalah metode kualitatif deskriptif. Pendekatan yang digunakan dalam penelitian ini adalah pendekatan objektif. Hasil menunjukkan bahwa kesedihan tokoh utama yang tergambar dalam kumpulan puisi karya Anne Bronte disebabkan oleh kerinduan, kesepian, serta kehilangan yang dilalui oleh tokoh utama dalam hidupnya.
\end{abstract}

Kata Kunci: Kesedihan, Struktur batin puisi, Tokoh utama

\section{PENDAHULUAN}

Kesedihan merupakan bagian dari emosi dalam diri manusia. Hal-hal yang menyebabkan kesedihan diantaranya; kerinduan, kesepian, kecewa, kehilangan dan kematian. Perasaan sedih dapat diungkapkan dengan ekspresi yang berbeda beda. Kesedihan juga sebagian dari pengalaman hidup yang tidak luput dari suka duka dan lika-liku kehidupan. Seseorang yang tengah bersedih biasanya ingin mengungkapkan perasaan hatinya dengan cara menangis, murung ataupun berdiam diri, tapi 
bagi sebagian orang cara mengatasi rasa sedih yang dialami yaitu dengan menuangkannya dalam rangkaian kata-kata yang menggambarkan isi hatinya dalam bentuk puisi.

Seperti halnya dalam kumpulan puisi Anne Bronte, sebagian dari puisinya menggambarkan kesedihan yang dialami oleh tokoh utama atas kerinduannya terhadap kehidupannya di masa lampau. Anne juga seringkali menggunakan pencitraan alam sebagai titik fokus puisi.

Berdasarkan latar belakang di atas, Peneliti tertarik untuk menganalisis kesedihan tokoh utama pada kelima puisi karya Anne Bronte di antaranya; The Bluebell, Memory, Home, The Consolation. Adapun judul penelitian ini yaitu "Kesedihan Tokoh Utama Dalam kumpulan Puisi Karya Anne Bronte"

\section{SUMBER DATA}

Sumber data pada penelitian ini menggunakan kumpulan puisi karya Anne Bronte. Fokus penelitiannya pada kesedihan tokoh utama pada kumpulan puisi karya Anne Bronte.

\section{METODE PENELITIAN}

Metode yang digunakan dalam penelitian ini adalah metode penelitian deskriptif kualitatif yaitu mendeskripsikan kesedihan tokoh utama dalam kumpulain puisi karya Anne Bronte melalui struktur batin puisi yang meliputi nada, rasa, tema dan amanat. Penelitian kualitatif adalah penelitian yang bermaksud untuk memahami fenomena tentang apa yang dialami oleh subjek penelitian, misalnya perilaku, persepsi, motivasi, tindakan, dan lain-lain, secara holistik, dan dengan cara deskripsi dalam bentuk kata-kata dan bahasa, pada suatu konteks khusus yang alamiah dan dengan memanfaatkan berbagai metode alamiah, Moloeng (dalam Egsavia 2021:10).

\section{KAJIAN TEORI}

Pendekatan penelitian yang digunakan oleh penelitian ini adalah Pendekatan Objektif. Pendekatan objektif yaitu pendekatan yang berfokus terhadap objek itu sendiri. Menurut (Yudiono, 1984: 53) "Pendekatan objektif ialah pendekatan sastra yang menekankan pada unsur intrinsik karya sastra yang bersangkutan. Juga sangat mengutamakan penyelidikan karya sastra berdasarkan realitas bacaan sastra itu sendiri."

Pendekatan objektif digunakan sebagai kaca mata dalam penelitian kali ini. Hal tersebut bertujuan untuk memperjelas penelitian mengenai kesedihan tokoh utama dalam kelima puisi Anne Bronte melalui struktur batin puisi yang mencakup Tema, rasa, nada dan amanat dalam puisi tersebut.

\section{HASIL DAN PEMBAHASAN}

\section{Struktur Batin Puisi}

Struktur batin puisi adalah unsur yang lebih menekankan pada penghayatan suatu puisi. Menurut I.A.Richards dalam (J.Waluyo1991:106) menyebutkan "deep structure is an abstract representation that identifies the ways a sentence can be analyzed and interpreted. Deep structure also consists of the essence of poetry which includes; theme, feeling, mandate, and tone." Richards mengungkapkan bahwa struktur batin itu dengan istilah hakikat puisi yang mengidentifikasi cara 
kalimat dapat dianalisis dan ditafsirkan, struktur batin puisi juga meliputi tema, nada, rasa dan amanat.

\section{Tema}

Tema merupakan suatu gagasan pokok atau ide pikiran yang ingin disampaikan oleh seorang penyair. Abrams (1970:78) menyatakan:

"Theme is sometimes used interchangeably with "motif," but the term is more usefully applied to a general concept or doctrine, whether implicit or asserted, which an imaginative work is designed to incorporate and make a persuasive to the reader, most themes are implied rather than explicitly staded. The theme is different from the superficial outlay of the text; it is normally the meaning of the text on a more abstract level."

Pernyataan Abrams tersebut menjelaskan bahwa tema terkadang digunakan bergantian dengan motif dan karya imajinatif dirancang untuk meyakinkan pembaca. Kebanyakan dari tema yang ada itu tersirat daripada dinyatakan dengan jelas.

Menurut Tarigan (1993:125): "Themes are certain world views or certain feelings about life or a certain set of values that form or construct the main idea of a literary work." Tarigan menjelaskan tema merupakan pandangan atau perasaan tertentu tentang kehidupan dari nilai-nilai yang membangun gagasan utama dari suatu karya sastra.

\section{Nada}

Keadaan hati yang ingin disampaikan oleh seorang penyair dalam puisi tentu memberikan nada tertentu sebagai pengekspresian suasana batin penyaerhadap kawan bicara, menurut I. A. Richard (dalam Abrams 1999:218): "tone as the expression of a literary speaker's "attitude to his listener. The tone of his utterance reflects his sense of how he stands toward those he is aiming to." Richard menjelaskan bahwa nada nada sebagai ekspresi tentang sikap pembicara terhadap pendengarnya. Nada ucapannya mencerminkan perasaannya tentang bagaimana dia berdiri terhadap orang yang dia tuju.

Senada dengan Richard Shipley (dalam Mansoer Pateda 2001:94) mengungkapkan: "Tone is the speaker's attitude towards the interlocutor. The aspect of tone is also related to the aspect of meaning which has the value of feel" Shipley menjelaskan bahwa nada adalah sikap yang disampaikan pembicara terhadap lawan bicaranya, nada juga berhubungan dengan aspek makna yang bernilai rasa. Dengan kata lain, hubungan antara pembicara dengan pendengar akan menentukan sikap yang tercermin dalam kata-kata yang digunakan. Nada yang dikemukakan oleh seorang penyair dalam suatu sajak memiliki keterkaitan atau hubungan dengan rasa yang terkandung pada sajak tersebut, karena penentuan nada harus sesuai dengan rasa yang tekandung dalam puisi yang di tulis oleh penulis tersebut.

\section{Rasa}

Rasa/perasaan adalah ungkapan atau ekspresi penyair kepada sesuatu yang dituangkan ke dalam puisinya. Chaplin (dalam Muhibbin Syah 2003:150) mengungkapkan: "Feeling is a state that experienced by each individual as a form of process resulting from the perception of actions that affect them. In this sense the situation is carried out on internal and external forces in the life that is 
carried out" Chaplin menjelaskan bahwa rasa/perasaan adalah sesuatu keadaan yang dialami pada setiap individu akibat dari dorongan internal atau eksternal atas respon terhadap suatu tindakan yang mempengaruhinya. Menurut Decrates (dalam Gunarsa 2003:24) mengungkapkan: "There are six basic feelings in each individual, such as; desire, hate, sorrow, wonder, love and joy." Menurut Decrates ada enam perasaan dasar dalam setiap individu yatu terbagi atas; hasrat, benci, sedih, heran, cinta dan kegembiraan.

\section{Amanat}

Amanat dalam puisi adalah pesan moral seorang penyair yang diharapkan menjadi sesuatu yang bermakna bagi para pembaca, menjadi hikmah, renungan, atau nasihat melalui karya puisinya tersebut. Menurut Nordquist (Waluyo 2017:142) "In rhetorical studies and communication studies, the message is the information conveyed by words in speech or writing, and/or other signs and symbols. A message verbal or non-verbal or both is the content of the communication process" Nordquist menjelaskan bahwa Dalam studi retoris dan studi komunikasi, pesan adalah informasi yang disampaikan melalui kata-kata dalam ucapan atau tulisan, dan / atau tanda dan simbol lainnya. Sebuah pesan verbal atau non verbal atau keduanya merupakan isi dari proses komunikasi.

Menurut Kenny (1966:89) menyatakan: "that moral message is likes a theme, if we see in the dichotomy of the fill of the literary. It can be a message wanted to give by the author to the readers, and it also hidden of the meaning." Kenny menjelaskan bahwa pesan moral atau amanat dapat diidentifikasikan sama dengan tema jika dilihat pada dikotomi sastra. Pesan moral atau amanat juga bisa menjadi pesan yang ingin disampaikan oleh penulis kepada pembaca, dan juga tersembunyi maknanya.

\subsection{Struktur Batin Puisi}

\section{Nada}

\section{Data 1}

"Is childhood, then, so all divine?

Or Memory, is the glory thine,

That haloes thus the past?

\section{Not ALL divine; its pangs of grief}

(Although, perchance, their stay be brief)

Are bitter while they last."

Pada data di atas, nada yang di ekpresikan oleh Bronte untuk menggambarkan kesedihan tokoh utama adalah nada kesal. Nada tersebut mengungkapkan kekesalan terhadap masa-masa yang telah dilalui di masa lampau, hal tersebut ditunjukkan oleh kalimat "Not ALL divine; its pangs of grief" larik tersebut menunjukkan kekesalan atas kenangan indah yang pernah dimiliki di masa lalu, ia mengungkapkan bahwa Hal-hal indah seperti itu tidak selalu manis tetapi hanya akan membawa pedihnya kesedihan kepada dirinya. Karena hal-hal indah yang ia miliki di masa lampau hanya akan selalu menjadi suatu kenangan dalam hidupnya yang tidak akan pernah ia miliki kembali. 


\section{Data 2}

"Now loud, it thunders o'er my head,

And now in distance dies.

But give me back my barren hills

Where colder breezes rise"

Pada data diatas, nada yang di ekpresikan oleh Bronte untuk menggambarkan kesedihan tokoh utama adalah nada keluhan terhadap kehidupan yang sedang ia jalani, seperti pada larik "Now loud, it thunders o'er my head" Hal tersebut menunjukkan ia sedang menjalani kehidupan yang berat dan sulit seakan akan semua kesulitan itu menggelegar seperti Guntur didalam kepalanya.

\section{Data 3}

\section{"Restore to me that little spot,}

With gray walls compassed round, Where knotted grass neglected lies, And weeds usurp the ground.”(2.B6.L21)

Pada data di atas, nada yang di ekpresikan oleh Bronte untuk menggambarkan kesedihan tokoh utama adalah nada berharap terhadap sesuatu yang dulu ia miliki yang sekarang tidak dapat dicapai, seperti pada larik "Restore to me that little spot" hal tersebut menunjukkan bahwa ia sedang sedang mencari dan berharap sesuatu untuk dikembalikan kepadanya yang diwujudkan dalam satu tempat tertentu.

\section{Rasa}

\section{Data 4}

"Still in the wallflower's fragrance dwell;

And hover round the slight bluebell, My childhood's darling flower.

Smile on the little daisy still,

The buttercup's bright goblet fill

With all thy former power.

Pada data di atas, rasa yang di diungkapkan oleh Bronte untuk menggambarkan kesedihan tokoh utama dalam puisi tersebut adalah rasa rindu akan kenangan indah dalam kehidupan masa lampau yang ditunjukkan melalui kalimat "My childhood's darling flower." Kalimat tersebut menunjukkan salah satu bunga yang mengingatkan tokoh utama betapa dirinya sangat rindu akan kenangan yang ia miliki di masa kecilnya dimana ia menyebutkan bahwa bunga Bluebell adalah salah satu bunga kesayangan masa kecilnya dan pada larik "The buttercup's bright goblet fill, With all thy former power." menunjukkan bahwa ia ingin mengisi kembali kehidupannya sekarang dengan hal hal indah yang ia miliki di masa lalu.

\section{Data 5}

"Nor is the glory all thine own,

For on our earliest joys alone

That holy light is cast. 
With such a ray, no spell of thine

Can make our later pleasures shine,

Though long ago they passed."

Pada data diatas, kali ini rasa yang diungkapkan oleh Bronte untuk menggambarkan kesedihan tokoh utama dalam puisi tersebut adalah rasa kehilangan yang ditunjukkan melalui kalimat "For on our earliest joys alone That holy light is cast.“ . Kalimat tersebut disampaikan oleh tokoh utama yang menunjukkan rasa kehilangan akan kebahagiaan yang pernah ia miliki dalam hidupnya di masa lampau, dimana tokoh utama tersebut menyampaikan bahwa kebahagiaan yang pernah ia miliki di ibaratkan sebagai cahaya suci yang hilang.

\section{Data 6}

"Though all around this mansion high

Invites the foot to roam,

And though its halls are fair within--

Oh, give me back my HOME!" (2.B7.L28)

Pada data diatas, rasa yang di ungkapkan oleh Bronte untuk menggambarkan kesedihan tokoh utama adalah rasa kehilangan dan kerinduan terhadap apa yang ia miliki sebelumnya, seperti pada larik "Oh, give me back my HOME!" hal tersebut menunjukkan dimana ia sangat merindukan dan ingin sekali kembali merasakan "rumah" yang ia miliki sebelumnya. Kata "rumah" dalam larik tersebut dapat memiliki artian tempat, seseorang atau hal tertentu.

\section{Tema}

Data 7

"BRIGHTLY the sun of summer shone

Green fields and waving woods upon,

And soft winds wandered by;

Above, a sky of purest blue,

Around, bright flowers of loveliest hue,

Allured the gazer's eye.

But what were all these charms to me,

\section{When one sweet breath of memory}

\section{Came gently wafting by?}

I closed my eyes against the day,

And called my willing soul away"

From earth, and air, and sky" (1.B1-2.L8-9)

Judul puisi menyoroti tema yang mendasari puisi tersebut. Pada data diatas, puisi yang berjudul "Memory" bertemakan tentang kepolosan masa kanak-kanak. hal ini sesuai dengan apa yang Bronte gambarkan melalui apa yang tokoh utama lakukan di sepanjang puisi tersebut, ia berbicara tentang kenangan yang ia miliki tentang pengalaman masa kecilnya. Tema di peroleh dengan menganalisis bagaimana Bronte menjelaskan peristiwa dan tempat, suasana yang mendasari puisi dan 
gambaran yang disajikan oleh pembicara/tokoh utama dalam puisi tersebut. Melalui ini, pembaca dapat menyadari bahwa tokoh utama dalam puisi tersebut sedang menceritakan kepolosannya sebagai seorang anak ketika dia memandang dunia sebagai tempat yang sempurna tanpa hiruk pikuk dan penderitaan, hal tersebut ditunjukkan di awal bait yang menggambarkan gambaran tentang indahnya kehidupan di masa lalu karena biasanya kenangan masa kecil penuh dengan kepolosan dan keindahan seperti yang di paparkan oleh tokoh utama dalam puisi tersebut. Ia juga menggambarkan kesedihannya atas kerinduan akan kehidupan masa kecilnya, hal tersebut dapat dilihat melalui kalimat seperti "When one sweet breath of memory came gently wafting by?" kalimat tersebut menunjukkan bahwa tokoh utama dalam puisi ini sedang mengingat dan merindukan betapa indahnya kehidupan yang dia miliki sebelumnya.

\section{Data 8}

"HOW brightly glistening in the sun

\section{The woodland ivy plays!}

While yonder beeches from their barks

Reflect his silver rays." (2.B1.L1-4)

Pada data diatas, puisi yang berjudul "Home" bertemakan tentang arti sebuah rumah. Hal ini sesuai dengan apa yang Bronte gambarkan melalui apa yang tokoh utama sampaikan bahwa arti rumah baginya berkaitan dengan kekaguman mereka terhadap alam, seperti pada larik "The woodland ivy plays!" dan "Reflect his silver rays." Hal tersebut menunjukkan bahwa latar adegan tersebut adalah hutan musim dingin, menyebabkan sinar matahari tampak berwarna perak menembus salju, dan menciptakan pemandangan yang romantis dari lanskap yang dingin.

\section{Amanat \\ Data 9 \\ "Nor is the glory all thine own, \\ For on our earliest joys alone \\ That holy light is cast.}

\section{With such a ray, no spell of thine}

Can make our later pleasures shine,

Though long ago they passed." (1.B8.L46-48)

Pada data di atas, Amanat yang disampaikan pada puisi Memory yaitu kebahagiaan tidak akan bersifat abadi. Kehidupan tidaklah akan selalu sama, hidup akan selalu berubah-ubah. Segala sesuatu yang kita miliki hanyalah bersifat sementara, begitupun dengan kebahagiaan.

\section{Data 10}

"Though all around this mansion high

Invites the foot to roam, And though its halls are fair within--

Oh, give me back my HOME!" (2.B7.L25-27)

Pada data di atas, Amanat yang disampaikan pada puisi "Home" yaitu bahwa arti sebuah rumah tidak selalu didefinisikan sebagai sebuah tempat atau sesuatu yang terlihat, tetapi lebih ditentukan oleh 
setiap orang berdasarkan sesuatu yang dirasakan untuk mendapatkan kenyamanan dan kenangan indah. bahkan tidak sedikit dapat mereka definisikan dengan benar.

\section{SIMPULAN}

Setelah melakukan analisis terhadap kesedihan tokoh utama dalam kumpulan puisi karya Anne Bronte, maka peneliti dapat menarik kesimpulan dari penelitian ini. Kesedihan tokoh utama dalam puisi disebabkan oleh kerinduan, kesepian serta kehilangan yang di alami oleh tokoh utama dalam hidupnya. Anne Bronte menggambarkan kesedihan Tokoh utama dalam kumpulan puisinya melalui gambaran gambaran masa lalu yang di lalui oleh tokoh utama tersebut, isinya menceritakan bahwa mereka telah kehilangan rekan atau orang-orang terdekatnya, bagaimana mereka sangat merindukan kehidupan masa lalunya, dan betapa mereka merasa sangat kesepian untuk melalui hariharinya tanpa orang-orang tercintanya.

\section{DAFTAR PUSTAKA}

Abrams, M.H. 1999. A Glossary of Literary Terms. USA: Longman Group

Anggito, Albi \& Joha Setiawan. 2018. Metode Penelitian Kualitatif. Sukabumi: CV Jejak

Egsavia, Chitra Nissa. (2021) Kehdupan Pernikahan yang Mempengaruhi Kepribadian Tokoh Amy dalam Novel Gone Girl Karya Gillian SchieberFlynn. Apollo Project: Jurnal Ilmiah Program Studi Sastra Inggris, 10 (1), 9-14

Syah, Muhibbin. 2003. Psikologi Belajar. Jakarta: PT. Rineka Cipta

Tarigan, H.G. 1993. Strategi pengajaran dan pembelajaran Bahasa. Bandung: Angkasa

Kenny, William. 1996. How to Fiction. New York. Simon \& Schcter, inc

Yudiono. 1984. Telaah Kritik Sastra Indonesia. Bandung: Angkasa

Waluyo, Herman J. 1991. Teori dan Apresiasi Puisi. Jakarta: Erlangga.

Gunarsa, S. D. 2003. Psikologi perkembangan. Jakarta: Gunung Mulia.

Mansoer, Pateda. 2001. Semantik Leksikal. Jakarta: Rineka Cipta. 